\title{
Two-phase flow patterns in horizontal rectangular minichannel
}

\author{
Fedor Ron'shin ${ }^{1, a}$ \\ ${ }^{1}$ Kutateladze Institute of Thermophysics, 630090, Lavrentiev ave. 1, Novosibirsk, Russia
}

\begin{abstract}
The two-phase flow in a short horizontal channel of rectangular cross-section of $1 \times 19 \mathrm{~mm}^{2}$ has been studied experimentally. Five conventional two-phase flow patterns have been detected (bubble, churn, stratified, annular and jet) and transitions between them have been determined. It is shown that a change in the width of the horizontal channels has a substantial effect on the boundaries between the flow regimes.
\end{abstract}

\section{Introduction}

In general, there is a rapid development of miniaturized heat exchangers. Recent studies show that the heat exchange systems with mini- and microscales are more energy efficient than the macro-systems with the channels greater than $1 \mathrm{~mm}$. The trend towards a decrease in characteristic sizes of devices in various technical fields determines development of studies on hydrodynamic and heat transfer in miniand microchannels. With decreasing of the channel height the ratio of surface area to channel volume increases inversely proportional to its minimal transverse size, and this causes high heat transfer intensity in the microsystems. In application to the processes in reacting systems, for instance, burning of combustible liquids in small channels, heat transfer intensification can either improve or deteriorate the situation [1].

There are a significant number of researches on the two-phase flow in mini- and microchannels. The review articles on two-phase flow in channels of different configurations can be found in [2-4]. Analysis of the researches shows that the structure of two-phase flow is generally influenced by the following parameters: channel geometry and dimensions, structure of the inlet section, fluid properties such as viscosity and surface tension. It is shown that in many studies round channels have been used, although rectangular channels have greater prospects for using in thermal stabilization systems. Flow patterns in the horizontal rectangular channel height below $1 \mathrm{~mm}$ are quite different from the classical two-phase flow regimes for horizontal channels with height more than $2 \mathrm{~mm}$ [4]. In the works of [5, 6] it is shown that the regimes of gas-liquid flow in the minichannels significantly depend on the conditions of phase input to the channel. In $[7,8]$ it is discussed the mechanisms influencing on the formation of patterns in mini- and microchannels. In the [9] there is an attempt to summarize various works on the study of two-phase flow in microchannels. It is shown that different authors use different criteria and distinguish different patterns of two-phase flow; thence, it is difficult to perform a comparison with other works.

\footnotetext{
${ }^{\text {a }}$ Corresponding author : f.ronshin@gmail.com
} 
The aim of present work is to study the patterns of two-phase flow and the boundaries between them in the short (length $80 \mathrm{~mm}$ ) rectangular channel cross-section of $1 \times 19 \mathrm{~mm}^{2}$, and compare it with the minichannel with cross-section of $1 \times 10 \mathrm{~mm}^{2}$.

\section{Experimental setup and technique of measurement}

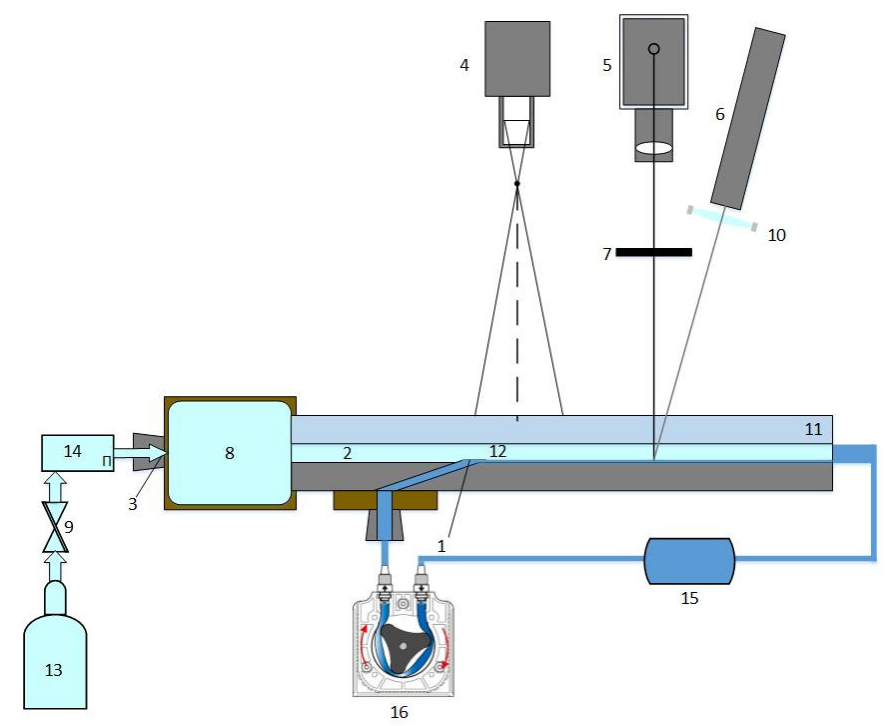

Figure 1. Schematic diagram of the experimental arrangement.

The schematic diagram of the experimental setup is demonstrated in figure 1 . The basic element of the test cells is a flat plate made of stainless steel with liquid nozzle (1). The stainless steel plate is placed on the textolite basement. The frame with the stainless steel plate is covered by optical window (11), so that rectangular minichannel (2) is created by the special metallic inserts with height $1 \mathrm{~mm}$.

The working liquid (pure distilled water) and the dry nitrogen from the gas bottle (13) have been used in the experiment. The working gas is supplied from the standard gas bottle ( 150 bars) (13). Initial gas pressure is set at 5 bars by pressure regulator (9) in order to provide a sufficient gas flow rate through the gas-controllers. A gas flow rate is regulated with the help of mass flow Bronkhost controller (14). Gas flow rate is varied from $0.51 /$ minute to $751 /$ minute. The working gas is supplied through the gas inlet (3) to the gas chamber (8). Water is supplied to the test cell by the Ismatec peristaltic pump (16) from a liquid container (15). The liquid flow rate is regulated in the range between $1 \mathrm{ml} / \mathrm{min}$ and $50 \mathrm{ml} / \mathrm{min}$. The water film is supplied from the liquid nozzle (1) of the height $50 \mu \mathrm{m}$. The film, formed in the nozzle (1), is driven along the channel by the moving gas. The mixture of vapor, gas and liquid and residual vapor is evacuated to the liquid container (15). The gas is evacuated to the atmosphere. All parameters have been recorded by the data acquisition systems, developed on the LabView software platform.

High-speed LIF (Laser Induced Fluorescence) technique has been used to study the two-phase flow in the mini-channel (1 mm height). This technique is described in more details in [10]. Distilled water with fluorophore Rhodamin $6 \mathrm{G}$ has been used for this optical method. The liquid-gas interaction in the channel is monitored in the region (12) by the digital video camera (4) and LIF technique. The "Aries" laser (6) with wavelength $532 \mathrm{~nm}$ and power of $50 \mathrm{~mW}$ is used to initiate fluorescence. The laser beam is unwrapped into the line (which is oriented orthogonally to the flow direction) by the cylindrical lens (10) which is placed at the distance $52 \mathrm{~mm}$ from the liquid entrance (1). The highspeed (up to $2.1 \mathrm{kHz}$ ) digital camera VS-Ld-751 (5) is used to register light from the liquid. The step low-pass filter (7) is placed in front of the lens of the camera to cut off laser emission which is reflected from the gas-liquid interface. 


\section{Results and discussion}

The flow patterns in the rectangular minichannel with cross-section of $1 \times 19 \mathrm{~mm}$ have been studied experimentally. The flow regime map has been created for the investigated channel (Fig. 1). The superficial gas and liquid velocities defined as the flow rates divided by the channel cross section area have been used as coordinates of this map. Following two-phase flow regimes have been registered: bubble, churn, annular, stratified and jet.

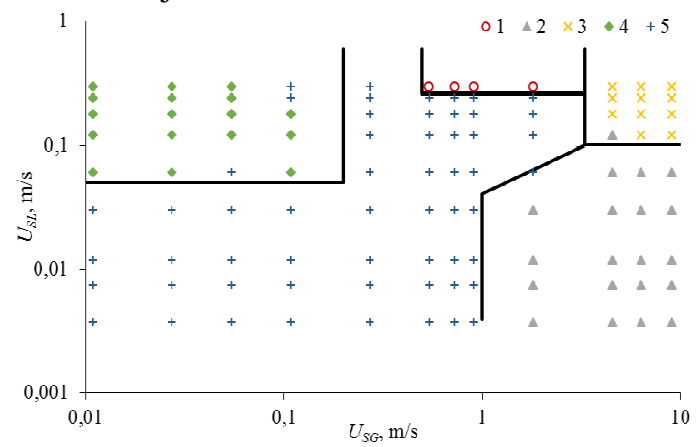

Figure 2. Map of two-phase flow in the minichannel with cross section of $1 \times 19 \mathrm{~mm}^{2}$. Flow regimes: (1) churn; (2) stratified; (3) annular; (4) bubble; (5) jet.

At very low superficial liquid velocities, gas moves in the central part of the channel, while the bulk of the liquid moves along the periphery of the side walls. Disturbances on the surface of the liquid are not detected. Stationary jet flow pattern is observed at low superficial liquid and gas velocities, when the gas flow occupied no more than half channel cross-section. The jet flow regime $\left(U_{S G}=0.027 \mathrm{~m} / \mathrm{s}, U_{S L}=0.03 \mathrm{~m} / \mathrm{s}\right)$ is demonstrated in figure $3 \mathrm{a}$. On the one of the sides of the channel, one can see the movement of the bubbles. This is transitional pattern to the bubble ones. By increasing the superficial liquid velocity, liquid pulsations occur in the sides of the channel. By increasing the superficial gas velocity (Fig. 3b), when the gas begins to occupy larger volume than the liquid, there is the transition to the stratified flow pattern. In this regime, part of the liquid moves along the bottom channel wall in the form of a film co-flowing with the gas stream. This regime is observed only in minichannels of a nonround shape, since the film in round tubes with small diameters is closed into a complete circle and thus establishes annular flow [11]. Figure 4a-d shows the time dependence of the liquid thickness distribution in the channel restored from an intensity of the light from fluorophore. In the range of high superficial liquid velocities $\left(U_{S L}>0.02 \mathrm{~m} / \mathrm{s}\right)$ the liquid pulsation can be observed in the lateral parts of the channel, fig $4 \mathrm{~d}$. By increasing superficial liquid velocity, liquid emissions occur from the lateral sides of the channel and one forms the film on the upper wall of the channel. There is the transition to the annular flow regime. This transition is monitored by digital video camera. The film in this pattern moves at the top and bottom walls of the channel. In the central part, the gas stream with the drops forms a core of the two-phase flow, fig 4c. Gas occupies most of the channel cross section, while the pulsating liquid movement occurs near with the lateral walls of the channel.
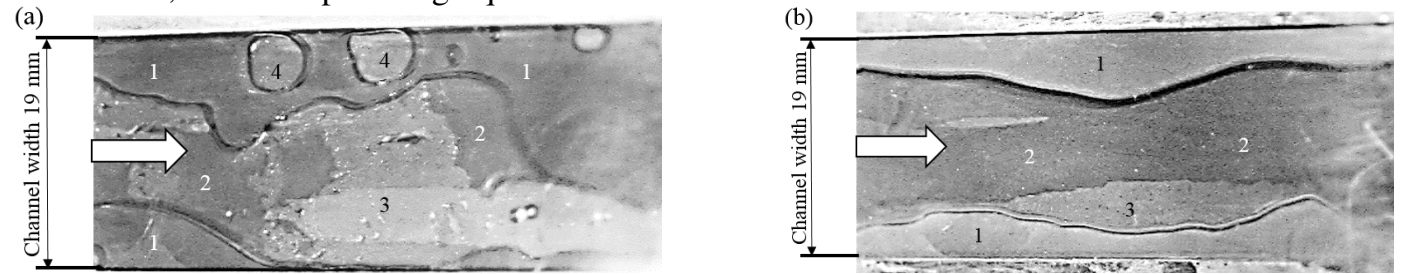

Figure 3. Photos of the jet flow pattern at: (a) $U_{S G}=0.027 \mathrm{~m} / \mathrm{s}, U_{S L}=0.03 \mathrm{~m} / \mathrm{s}$; (b) $U_{S G}=1.818 \mathrm{~m} / \mathrm{s}, U_{S G}=0.12$ $\mathrm{m} / \mathrm{s} ; 1$ - liquid, 2 - liquid film on the bottom channel wall, 3 - not wetted bottom channel wall, 4 - gas bubbles.

At high superficial liquid velocities and low superficial gas velocities, the bubble flow regime is observed. In this flow pattern, the liquid moves through the channel, containing many small gas bubbles, fig $4 \mathrm{a}$. The size and amount of the bubbles are changed depending on the liquid and gas flow 
rate, but the bubble sizes are always smaller than the channel width. With increasing superficial liquid and gas velocities, the bubble frequency increases. By increasing the superficial gas velocity, the breaks in the bridges begin to appear, the transition to the churn flow regime takes place, fig $4 \mathrm{a}$. This flow pattern is discussed in more details in [12].

Figure 4 shows comparison of two regime maps for the minichannels cross-section of $1 \times 19 \mathrm{~mm}$ and $1 \times 10 \mathrm{~mm}$ and the typical flow patterns in the channel $1 \times 10 \mathrm{~mm}$. The two-phase flow patterns in the channels do not differ, but the boundaries between them shift significantly. With an increase in channel width, the area of churn and jet regimes increase significantly, reducing the area of bubble regime. The areas of stratified and annular regimes remain practically unchanged.

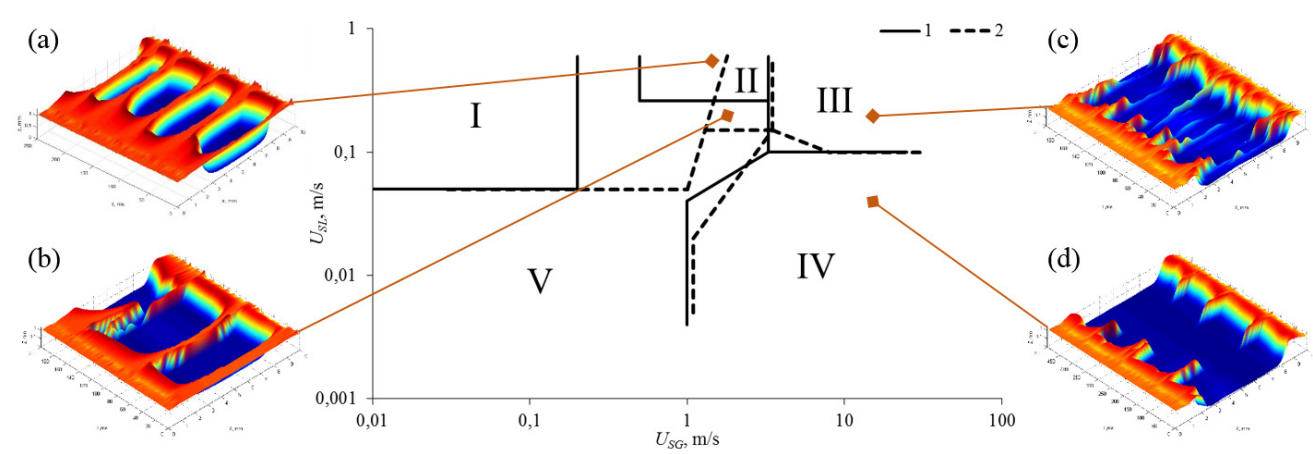

Figure 4. Comparison of the maps of flow regimes for the channels with cross sections (1) $1 \times 19 \mathrm{~mm}^{2}$, (2) $1 \times 10$ $\mathrm{mm}^{2}$; flow regimes: (I) bubble, (II) churn, (III) annular, (IV) stratified and (V) jet. Flow patterns in the channel cross-section of $1 \times 10 \mathrm{~mm}^{2}$ : (a) bubble, (b) churn, (c) annular, (d) stratified

In conclusion, it is should be noted that the features of the two-phase flow patterns have been defined in the channel with height of $1 \mathrm{~mm}$ and width of $19 \mathrm{~mm}$. It is shown that the channel width has significant effect on the boundaries of two-phase flow regimes.

We gratefully acknowledge the support from the Ministry of Education and Science of Russia (№ 14.604.21.0053 Project identifier RFMEFI60414X0053).

\section{References}

1. V. V. Zamashchikov, A. A. Korzhavin, E. A. Chinnov, Combust. Explos. Shock Waves 50, 381 (2014)

2. N. Shao, A. Gavriilidis, P. Angeli, Chemical Engineering Science 64, 2749 (2009)

3. E. A. Chinnov, O. A. Kabov, High Temp. 44, 773-791 (2006)

4. E. V. Rebrov, Theor. Found. Chem. Eng. 44, 355 (2010)

5. V. Haverkamp, V. Hessel, H. Löwe et al., Chem. Eng. Technol. 29, 1015 (2006)

6. O. A. Kabov, E. A. Chinnov, V. Cheverda, Microgravity sci. technol. XIX-3/4, 44-47 (2007)

7. E. A. Chinnov, V. V. Guzanov, O. A. Kabov, Tech. Phys. Lett. 35, 653-656 (2009)

8. E. A. Chinnov, F. V. Ron'shin, O. A. Kabov, Int. J. Multiphase Flow 80, 57-68 (2016)

9. J.R. Thome, A. Bar-Cohen, R. Revellin, I. Zun, Exp. Therm. Fluid Sci. 44, 1 (2013)

10. E. A. Chinnov, Journal of Heat Transfer 138, 7 (2016)

11. A. Barajas, R. L. Panton, Int. J. Multiphase Flow 19, 337 (1993)

12. E. A. Chinnov, F. V. Ron'shin, V. V. Guzanov, D. M. Markovich, O. A. Kabov, High Temp. 52, 681-687 (2014) 